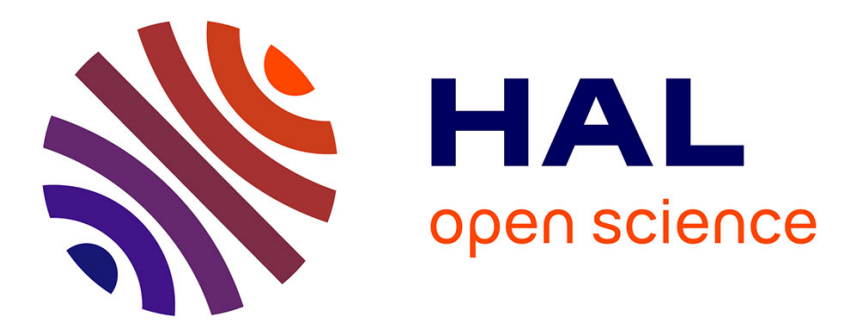

\title{
Experimental analysis of compaction of concrete and mortar
}

\author{
Nicolas Burlion, Gilles Pijaudier-Cabot, Noël Dahan
}

\section{To cite this version:}

Nicolas Burlion, Gilles Pijaudier-Cabot, Noël Dahan. Experimental analysis of compaction of concrete and mortar. International Journal for Numerical and Analytical Methods in Geomechanics, 2001, 25 (15), pp.1467-1486. 10.1002/nag.178 . hal-01006829

\section{HAL Id: hal-01006829 \\ https://hal.science/hal-01006829}

Submitted on 31 Jul 2017

HAL is a multi-disciplinary open access archive for the deposit and dissemination of scientific research documents, whether they are published or not. The documents may come from teaching and research institutions in France or abroad, or from public or private research centers.
L'archive ouverte pluridisciplinaire $\mathbf{H A L}$, est destinée au dépôt et à la diffusion de documents scientifiques de niveau recherche, publiés ou non, émanant des établissements d'enseignement et de recherche français ou étrangers, des laboratoires publics ou privés. 


\title{
Experimental analysis of compaction of concrete and mortar
}

\author{
Nicolas Burlion ${ }^{1}$, Gilles Pijaudier-Cabot ${ }^{2}$ and Noël Dahan ${ }^{3}$ \\ ${ }^{1}$ Laboratoire de Mécanique de Lille, EUDIL, Bd Paul Langevin, 59655 Villeneuve d'Ascq Cedex, France \\ ${ }^{2}$ R\&DO, Laboratoire de Génie Civil de Nantes - Saint Nazaire, Ecole Centrale de Nantes, BP 92101, Nantes Cedex 3, France \\ ${ }^{3}$ LMT-Cachan, ENS Cachan/CNRS/Université P. et M. Curie, 61 avenue du Président Wilson, F-94235 Cachan Cedex, France
}

\begin{abstract}
Compaction of concrete is physically a collapse of the material porous microstructure. It produces plastic strains in the material and, at the same time, an increase of its bulk modulus. This paper presents two experimental techniques aimed at obtaining the hydrostatic response of concrete and mortar. The first one is a uniaxial confined compression test which is quite simple to implement and allows to reach hydrostatic pressures of about $600 \mathrm{MPa}$. The specimen size is large enough so that concrete with aggregate sizes up to $16 \mathrm{~mm}$ can be tested. The second one is a true hydrostatic test performed on smaller (mortar) specimens. Test results show that the hydrostatic response of the material is elasto-plastic with a stiffening effect on both the tangent and unloading bulk moduli. The magnitude of the irreversible volumetric strains depends on the initial porosity of the material. This porosity can be related in a first approximation to the water/cement ratio. A comparison of the hydrostatic responses obtained from the two testing techniques on the same material show that the hydrostatic response of cementitious materials cannot be uncoupled from the deviatoric response, as opposed to the standard assumption in constitutive relations for metal alloys. This feature should be taken into account in the development of constitutive relations for concrete subjected to high confinement pressures which are needed in the modelling of impact problems.
\end{abstract}

KEY WORDS: concrete; mortar; compaction; experimental methods; hydrostatic response; deviatoric response

\section{INTRODUCTION}

When subjected to high confinement compressive stresses, the non-linear response of concrete is not only the result of microcracking and microcrack sliding but also the consequence of material crushing. The mortar surrounding the aggregate is a porous material and if the hydrostatic pressure applied on the material is sufficiently high, the mortar porosity can be decreased 
irreversibly. The material is compacted mechanically. This type of material degradation, called 'compaction' in the remaining of this paper, is encountered for instance in impact problems, e.g. on concrete slabs: concrete near the impactor is subjected to a state of stress close to uniaxially confined compression because of the intertia effect provided by the material far from the impactor.

In constitutive models, the usual practice is to split the deviatoric and hydrostatic responses of the material and to consider that these two are independent. Constitutive relations based on this principle exist in several commercial finite element software dedicated to transient analyses (see e.g. References $[1,2])$. In order to calibrate these models, it is necessary to obtain experimentally the so-called 'equation of state' of the material, i.e. the relationship between the volumetric deformation of the material and the applied hydrostatic stress (first invariant of the stress tensor). The deviatoric response can be obtained quite easily with standard uniaxial compression tests. The characterization of the equation of state for hydrostatic pressures ranging up to $1 \mathrm{GPa}$ remains an open problem.

Most of the testing methods available in the literature deal with the response of concrete subjected to moderate triaxial confinement. Their aim is to capture the brittle-ductile transition of the material response which is characteristic of cohesive frictional materials [3]. Results obtained from experiments in triaxial cells on cylindrical specimens, similar to those used in soil mechanics, deal usually with hydrostatic pressures up to $100 \mathrm{MPa}$ approximately (see e.g. References [4-6]). True triaxial compression tests, such as those performed by Winkler [7] and Schikert and Danssman [8] present the same limitations as far as the range of hydrostatic pressure is concerned.

These experimental techniques deal with quasistatic experiments. There are methods in dynamics which can be used in order to characterize the equation of state such as the plate/plate experiment (see e.g. Reference [9]). These testing methods, however, remain quite difficult to implement since each experimental point on the hydrostatic response refers to a single experiment. Furthermore, this type of experiments yields very high pressures, larger than the stresses obtained in classical impact problems on a concrete structure.

In geophysics and rock mechanics, several authors have developed experimental techniques where rocks are subjected to very high pressures, up to $5 \mathrm{GPa}$, and high temperature (up to $1700^{\circ} \mathrm{C}$ ). Among those, one can mention the comprehensive works of Bridgman [10], Boyds [11] and Leger [12]. The major limitation of these techniques is related to the size of the specimen tested which remains very small, and in all cases, not compatible with the minimum specimen sizes required for testing concrete as a homogeneous material. Nevertheless, Bazant et al. [13] have used one of this experimental technique in order to obtain the curve relating the hydrostatic pressure to the volumetric deformation for cement paste and mortar. The experimental method consists in placing a cylindrical specimen (height $44.4 \mathrm{~mm}$, diameter $18.8 \mathrm{~mm}$ ) in a very rigid hollow plate which prevents lateral deformation (see Figure 1). The specimen is then subjected to compression parallel to its vertical axis. The plate provides a passive lateral confinement and the loading path applied to the material is similar to the one applied in oedometric compression tests in soil mechanics. This set-up, which is very simple compared to dynamic tests, enabled the authors to reach very high hydrostatic pressures of the order of several GPa. In this paper, we are going to extend the principle of this test, further denoted an uniaxial confined experiment, to concrete.

A pending issue in the constitutive models for concrete under high confinement is whether the hydrostatic and deviatoric responses of the material should be coupled or not. In metal alloys, it is 


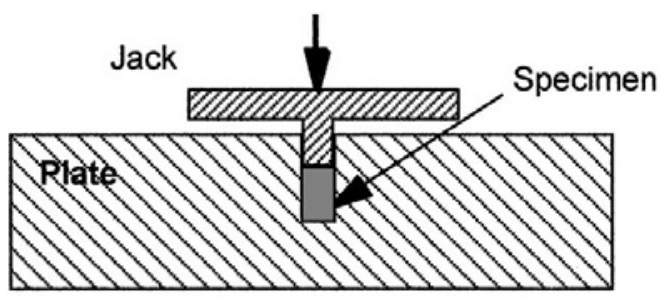

(a)

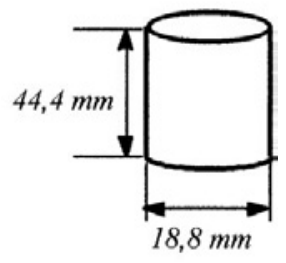

(b)

Figure 1. Principle of Bazant's oedometric test.

classically assumed that these two material responses are independent which is, in fact, a great simplification of the constitutive models where the plastic response can be captured with standard yield functions. In the second part of the paper, we will present experimental result obtained from true hydrostatic compression tests and compare them with the results from the uniaxial confined experiment in order to demonstrate that, for mortars, the hydrostatic and deviatoric responses are indeed coupled.

\section{UNIAXIAL CONFINED EXPERIMENT}

This experimental technique has been developed on the basis of the testing method used by Bazant et al. [13] which was adapted from the works of Bridgman (see Reference [3]). The principle of the test is the same, although the specimen dimensions and the cell design have been chosen in order to accommodate concrete samples and to measure the volumetric strain of the specimen. Figure 2 shows a description of the apparatus. A cylindrical specimen of height $100 \mathrm{~mm}$ and diameter $50 \mathrm{~mm}$ is placed into a hollow steel tube, denoted later as confinement cell, and loaded vertically with a $2500 \mathrm{kN}$ testing frame. The inner diameter of the confinement cell is $53 \mathrm{~mm}$ and the outer diameter is $140 \mathrm{~mm}$. This device applies a passive confinement on the concrete specimen by preventing lateral expansion. The cylinder and the jack which applies the vertical load have been made of hardened steel which remains elastic. An elastic radial deformation of the steel jack is expected and it is necessary that the diameter of the jack by slightly less than the diameter of the cell, but equal to the diameter of the specimen. The specimen size allows to test concrete with aggregate sizes up to $16 \mathrm{~mm}$. It is cast in separate moulds and placed in the cell afterwards. This is the reason why the inner diameter of the cell is slightly larger than the diameter of the concrete specimen.

The gap between the specimen and the cell is filled with epoxy CHRYSOR ${ }^{\circledR}$ C6120. It is extremely important, however, to avoid any gap in between concrete and steel, otherwise the specimen might be damaged at the beginning of the vertical loading as confinement is not effective. Epoxy is placed on the bottom of the cell and the specimen is slowly descended into the cell. As a result, epoxy fills this gap starting from the bottom of the cell and moving upwards so that air bubbles are avoided. Prior to placing the specimen in the cell, a Teflon ${ }^{\circledR}$ coating is applied on its inner surface in order to minimize friction.

In the development of this apparatus, we faced two major problems: (i) strain and confinement measurements and (ii) the characterization of the concrete/steel interface and the inherent friction 

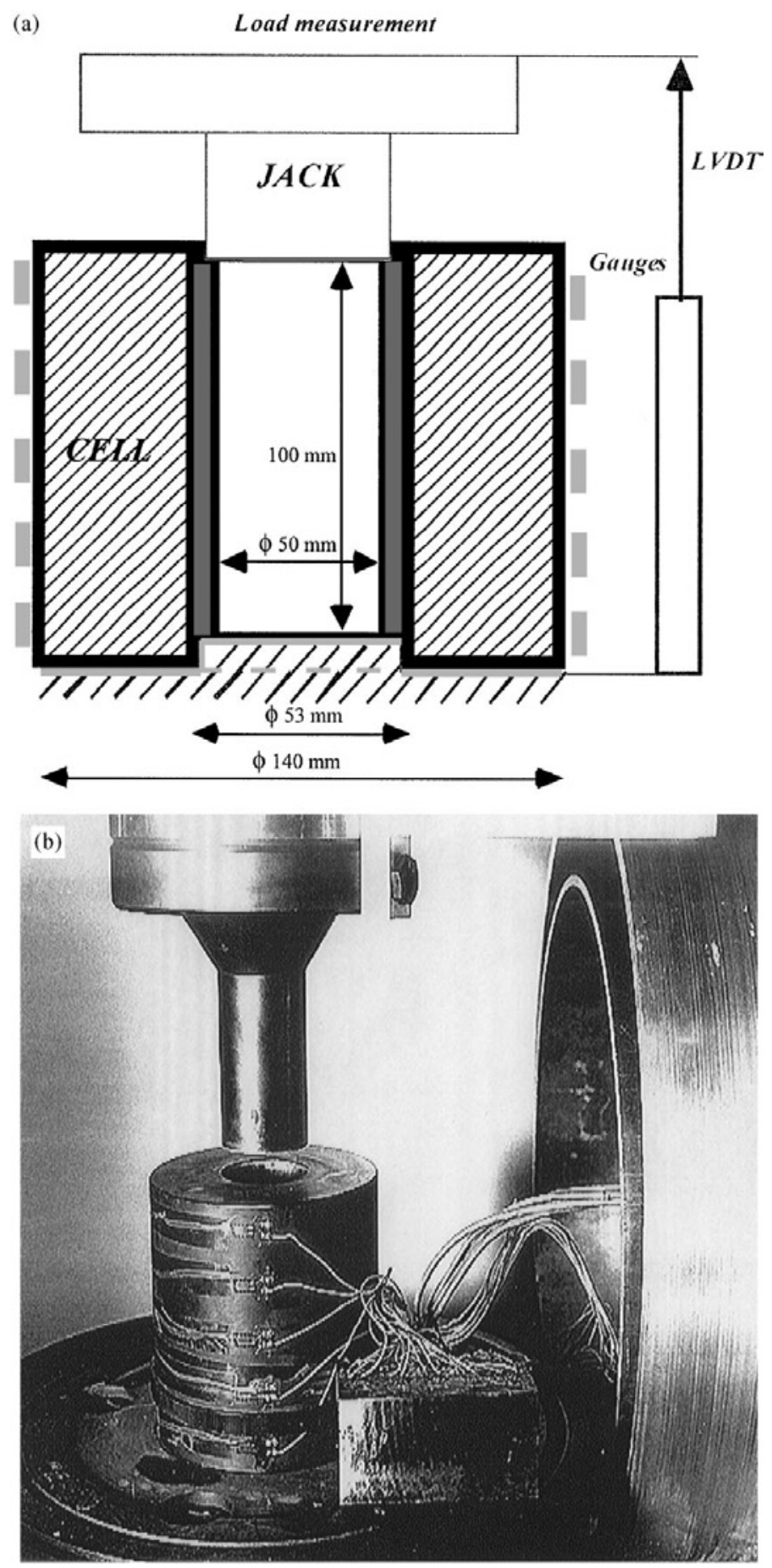

Figure 2. (a) Principle of uniaxial confined compression test. (b) Uniaxial confined compression test. 


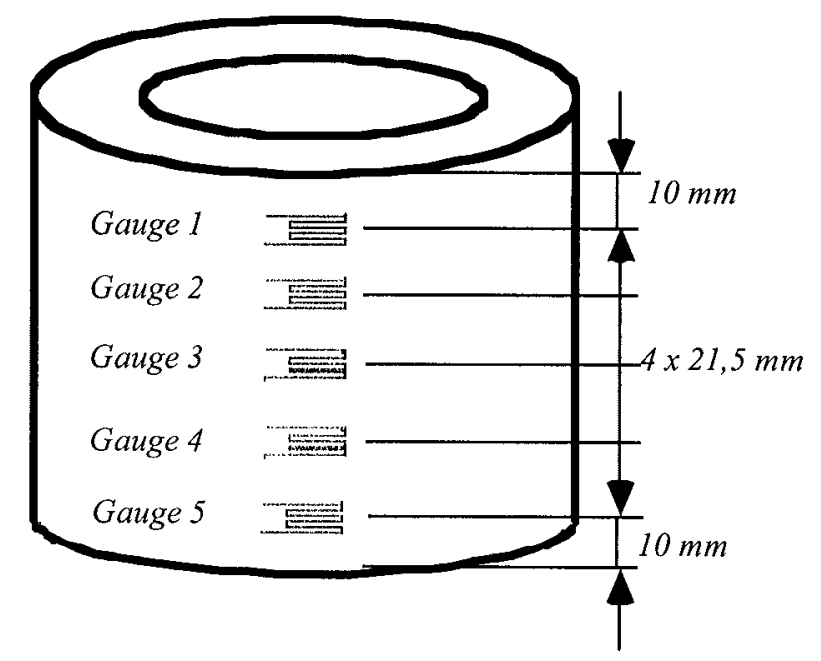

Figure 3. Measurement technique: strain gauges arrangement.

in the course of loading. We are going to describe in detail the proposed solutions to these problems in the next two sections.

\subsection{Measurement technique}

In Bazant's tests, the lateral expansion of the specimen is assumed to be completely prevented. This is due to the special geometry of the testing apparatus in which the specimen is sufficiently small and the plate is sufficiently stiff so that its deformation can be neglected. In the present experiments, and considering the dimension of the concrete specimen, it was quite difficult to devise a similar testing apparatus. We chose to use the confinement cell as a measurement device for the lateral expansion and for the applied confinement stress at the same time. The basic idea is that the cell deforms elastically during the test. Hence, its entire deformation and the pressure applied by concrete on the inner part of the steel tube can be deduced from transverse strain measured on the outer (external) diameter of the cell, with the help of standard elasticity formulas. The steel tube has been equipped with five couple of strain gauges on its external surface as shown on Figure (3). We used Vishay-Micromesure ${ }^{\circledR}$ gauges type CEA-06-250UN-120, stuck with the glue VM AE-15 $\left(1 \mathrm{~h}\right.$ at $\left.100^{\circ} \mathrm{C}\right)$. Gauges are diametrically disposed, and mounted in complete extensometric bridge with balancing gauges. The purpose of placing these gauges regularly spaced on the height of tube was to evaluate the influence of friction as discussed later on. From the measurement of the external radial deformation of the cell $\varepsilon_{r r}^{\mathrm{e}}$, and assuming that it is constant over the height of the cell, the radial stress applied to concrete $\sigma_{r r}$ and the radial deformation of the inner surface of the cell $\varepsilon_{r r}^{\mathrm{i}}$ are

$$
\begin{gathered}
\sigma_{r r}=E \frac{r_{\mathrm{e}}^{2}-r_{\mathrm{i}}^{2}}{2 r_{\mathrm{i}}^{2}} \varepsilon_{r r}^{\mathrm{e}} \\
\varepsilon_{r r}^{\mathrm{i}}=\left(\frac{1-v}{2}+\frac{1+v}{2} \frac{r_{\mathrm{e}}^{2}}{r_{\mathrm{i}}^{2}}\right) \varepsilon_{r r}^{\mathrm{e}}
\end{gathered}
$$




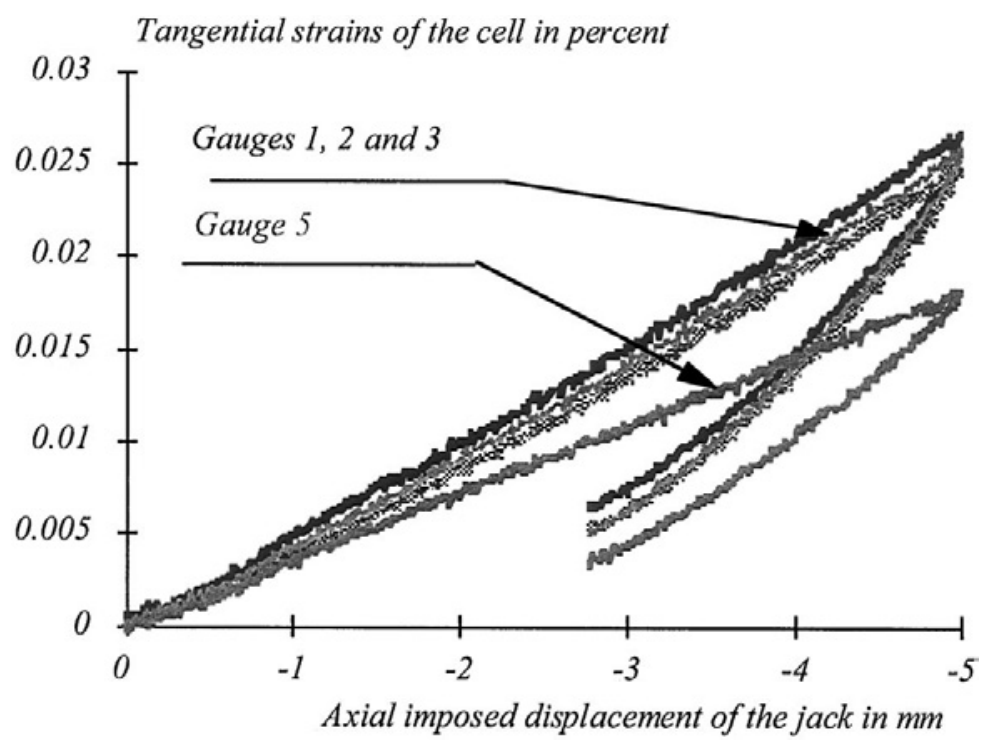

Figure 4. Deformation of the cell: axial displacement versus radial strains curves.

where $E$ and $v$ are the Young's modulus and the Poisson ratio of the steel used for the cell, respectively $(E=210 \mathrm{GPa}, v=0.3) . r_{\mathrm{i}}$ and $r_{\mathrm{e}}$ are the internal and external radii of the cell, respectively.

The vertical deformation of the cylinder is measured with a standard LVDT and the load cell of the testing machine provides the measurement of the applied vertical stress. Under the assumption that the deformation is homogeneous in the concrete cylinder and that the epoxy used for the steel concrete interface is incompressible, the axial strain of the specimen is computed as the vertical displacement divided by the specimen height. The deformation of the steel jack is subtracted in order to obtain the concrete axial strain. The radial strain in concrete is approximately equal to the strain computed on the inner surface of the cell according to Equation (2) (the gap in between concrete and steel is negligible). The confinement stress applied on concrete is provided by Equation (1) and the load cell of the testing machine provides the vertical stress (load divided by the area of the cross-section of concrete).

\subsection{Steel concrete interface and influence of friction}

The above data interpretation strongly relies on the facts that the specimen deforms homogeneously and that the deformation of the epoxy layer is negligible. Inhomogeneous deformations can result from the friction in between epoxy and the confinement cell as the vertical load is applied. In order to evaluate the validity of this assumption and to characterize the response of the epoxy, an aluminium specimen was tested first. Its geometry was exactly the same as the geometry of the concrete specimen. Aluminium was chosen because of its ratio of Young's modulus to Poisson's coefficient ratio is almost the same as concrete. Figure 4 shows the radial strains measured with the first three gauges and the last one (going from the top to the bottom of the cell) on the outer surface of the cell versus the longitudinal displacement. It is clear from these curves that friction 


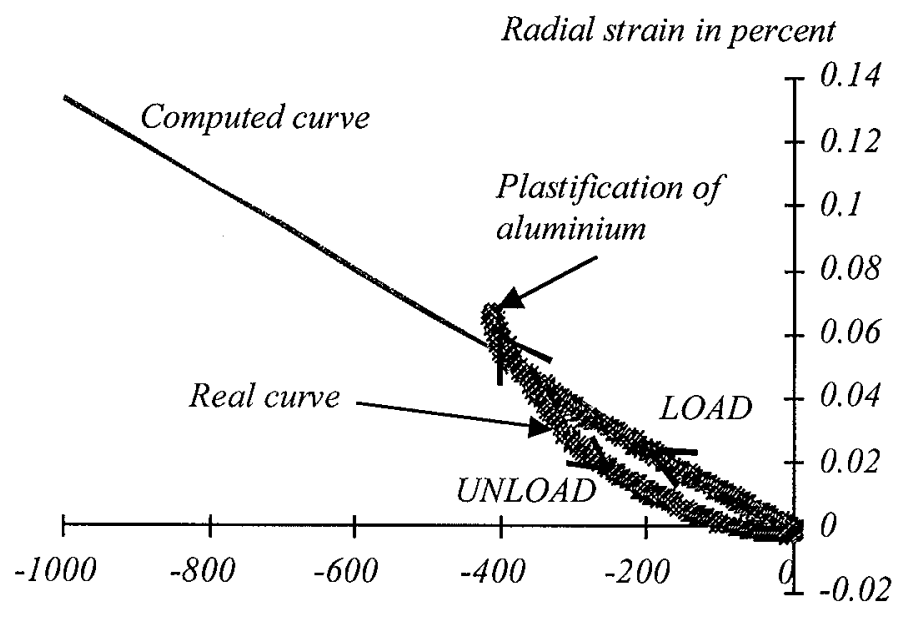

Applied axial stress in $M P a$

Figure 5. Comparison between calculation and experiment for aluminium subjected to uniaxial confined compression.

does not affect the homogeneity of the cell deformation on, at least, the top half-part because the gauge responses are almost the same. The strong deviation of the last (bottom) gauge information compared to the others may result both friction from in between the specimen and the cell and also from that between the cell and the bottom plate where it rests during the test.

We will assume in the remaining part of the paper that confinement is homogeneous under the total cylindrical surface of the specimen, but only the first three gauges will be used in order to deduce the radial stress and the radial strain of concrete. Thus, additional confinement at the bottom of the specimen due to friction is neglected in the test data interpretation. As a consequence, the axial strain is slightly under-estimated because the most confined part of the specimen deforms less.

A second check consists in comparing the relation between the applied vertical stress on the specimen and the lateral expansion of the inner diameter of the cell. With the aluminium specimen, this relation can be obtained theoretically, under the assumption that the influence of epoxy is neglected. The transverse deformation of the aluminium specimen can be computed theoretically for any vertical load corresponding to a confinement deduced from Equation (1), given Young's modulus and Poisson's ratio of the material. It can be compared, at the same vertical load levels, with the transverse strain computed from the cell response given in Equation (2). Figure 5 shows this comparison both in the case of loading and unloading. The deviation of the experimental curve at the maximum applied stress should not be considered in this figure because the specimen entered the plastic regime. Overall, the correlation between the two measures of the transverse strain is very good, especially for monotonic loading. Some friction occurs during unloading which produces a slight, still acceptable, deviation. It follows from these results that the layer of epoxy can be viewed as thin enough and can be considered as incompressible in the interpretation of the test data. It can be also concluded that it is possible to obtain the strains and stress applied to the concrete specimen according to the formulae in 


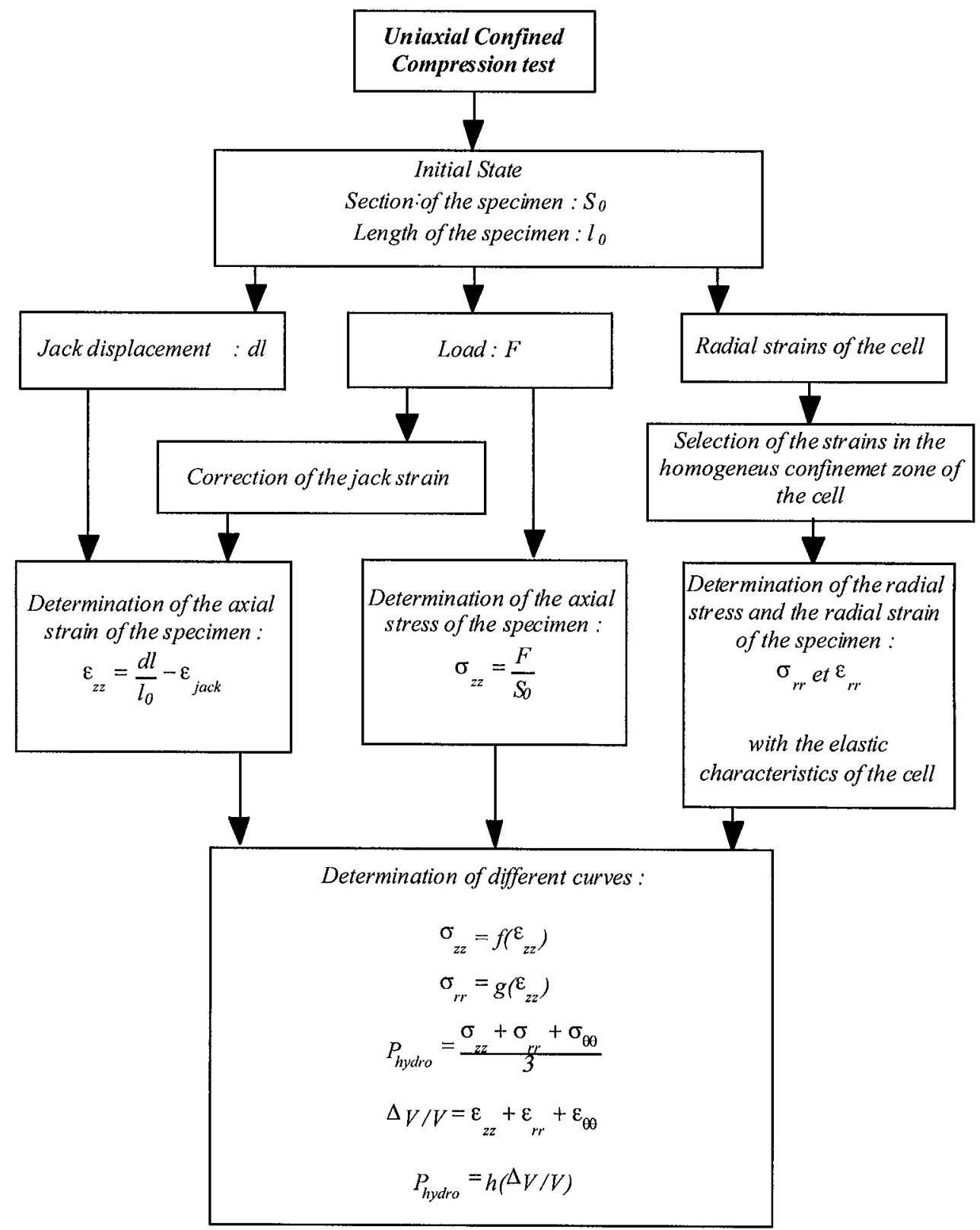

Figure 6. Summary of data interpretation method.

Equations (1) and (2) and provided that the information of one of the three top gauges of the cell are used for measuring its outer transverse strain.

In the test data interpretation, the average of the three gauges information will be used. The analysis of the uniaxial confined compression test is summarized in Figure 6. The different steps of 


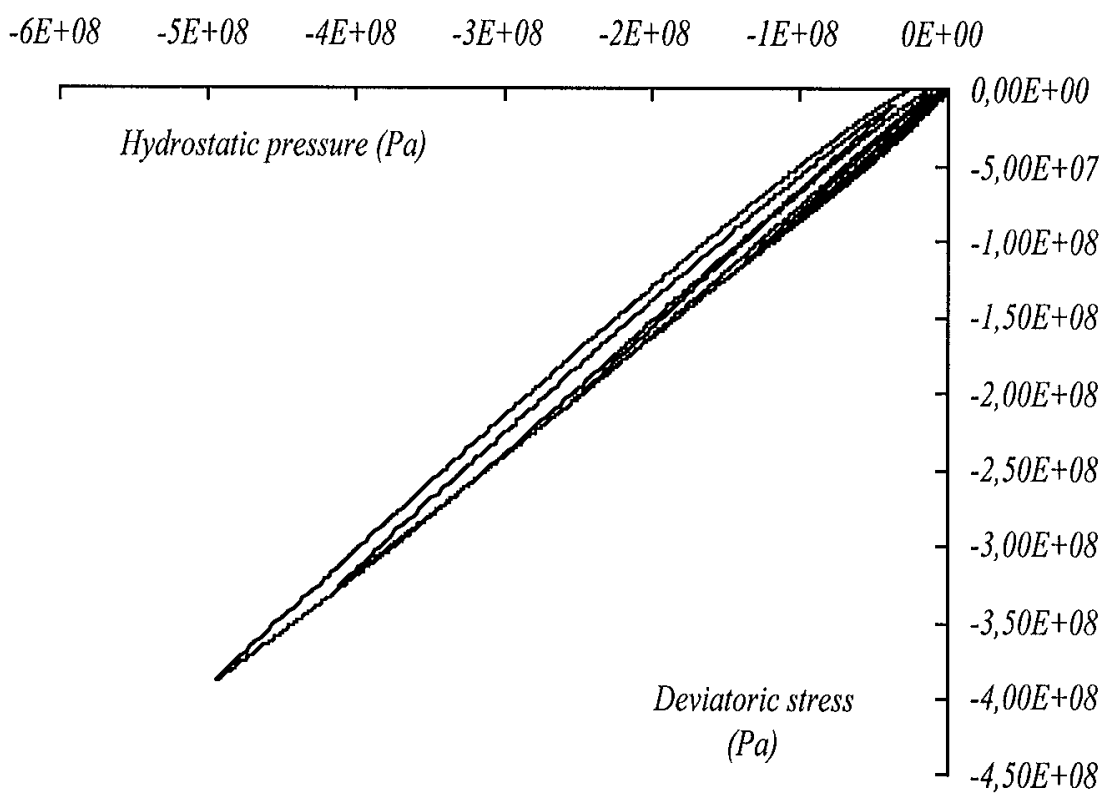

Figure 7. Hydrostatic pressure versus stress deviator curve for a motor.

data treatment are presented. During the tests, the jack is displacement controlled. The strain rate is small, equal to $10^{-4} \mathrm{~s}^{-1}$.

\subsection{Results on mortar and concrete}

Figure 7 shows the loading path applied to a mortar specimen during the test. It is clearly linear in the stress plane. The difference between the loading and the unloading is due to friction between the cell and concrete. Friction is larger during unloading and provokes the loops of this curve, same as the result in Figure 5.

In order to observe the influence of the porosity on the response of the material, three types of mortar specimens made with different mixes have been considered. The water to cement ratios $(W / C)$ for the three mixes are $0.3,0.5$, and 0.8 , respectively. The more the water content, the more porous the material is expected to be and the more the material is prone to compaction due to pore crushing. Table I shows the different mix proportions. The specimens were removed from their moulds two days after casting and kept in the laboratory before testing. Figure 8 shows the experimental results obtained for the mortar with $W / C=0.5$. Two plots with the evolution of the axial strain versus the axial stress and the axial strain versus the radial stress are shown. These figures shows that after a small elastic regime, the material response is elasto-plastic. The increase of the tangent modulus (with the increase of the unloading modulus as we will see on concrete) is due to the compaction process. As the pores are progressively crushed, the material becomes stiffer. The shape of these curves is similar to those obtained by Bazant et al. [13].

Figure 9 shows the three different responses obtained for the three mortar mixes. As expected, the higher the water to cement ratio (i.e. porosity), the larger the irreversible volumetric strain, 
Table I. Mixes of tested mortars.

\begin{tabular}{ll}
\hline$W / C=0.3$ & Amount \\
\hline Sand $\ll$ Leucat $\gg 0 / 2 \mathrm{~mm}$ & $1350 \mathrm{~kg} / \mathrm{m}^{3}$ \\
Cement CPJ CEM IIb 45 & $450 \mathrm{~kg} / \mathrm{m}^{3}$ \\
Water & $135 \mathrm{~kg} / \mathrm{m}^{3}$ \\
Super plasticizer & $9 \mathrm{~kg} / \mathrm{m}^{3}$ \\
$W / C=0.5$ & Amount \\
\hline Sand $\ll$ Leucat $\gg 0 / 2 \mathrm{~mm}$ & $1350 \mathrm{~kg} / \mathrm{m}^{3}$ \\
Cement CPJ $/$ CEM IIb 45 & $450 \mathrm{~kg} / \mathrm{m}^{3}$ \\
Water & $225 \mathrm{~kg} / \mathrm{m}^{3}$ \\
$W / C=0.8$ & $\mathrm{Amount}$ \\
\hline Sand $\ll$ Leucat $\gg 0 / 2 \mathrm{~mm}$ & $1350 \mathrm{~kg} / \mathrm{m}^{3}$ \\
Cement CPJ $/$ CEM IIb 45 & $450 \mathrm{~kg} / \mathrm{m}^{3}$ \\
Water & $360 \mathrm{~kg} / \mathrm{m}^{3}$ \\
\hline
\end{tabular}

which is an experimental evidence of material compaction. Note that the experimental device allows to reach hydrostatic pressures up to $600 \mathrm{MPa}$. This limitation is due to the capacity of the uniaxial testing machine and to the material property of the steel jack which should not enter the plastic regime. According to computations, this range of hydrostatic pressure is sufficient in order to deal with impact problems at moderate speed, i.e. a few hundred m/s (see e.g. Reference [14]).

Figure 10 shows the test data obtained for concrete in terms of axial displacement of the jack versus axial load applied on concrete. The mix proportion is given in Table II. The data correspond to the first mix with a $W / C$ ratio of 0.5 . Compared to mortars, the initial elastic regime is slightly larger and the irreversible volumetric strain is smaller. This is due to the aggregate skeleton which can hardly be compacted at such values of hydrostatic pressures. Nevertheless, the shape of the curve is similar to that of mortar with a stiffening effect. The stiffening effect on the unloading modulus is shown better in Figure 11 where Young's modulus of the material is plotted as a function of the total volumetric strain encountered prior to unloading. Young's modulus has been computed assuming that Poisson's ratio of the material remains constant during compaction. Its measurement was performed in the linear portion of the loading response of the specimen after unloading. The non-linear portion of this curve, for small hydrostatic pressures, was not considered as it may be influenced by friction between the cell and the specimen. Compaction produces an increase in Young's modulus of concrete of about 30 per cent.

Finally, it is interesting to observe the structure of the material after compaction. Figure 12 shows a longitudinal cross-section of the material before and after the test. It is observed that crushing in the mortar phase in between the aggregates has provoked a slight rearrangement of the aggregate skeleton. Aggregate pieces are more or less oriented horizontally and the material looks like it was stratified. If the material would be subjected to pure hydrostatic stresses, such an rearrangement of the material would not be expected because the applied load is essentially isotropic. Hence, it is expected that the volumetric deformation versus hydrostatic curves measured in the uniaxial confined experiment and in a hydrostatic compression test should be rather different since they yield a different structure of the compacted material, with less motion of the aggregate skeleton. 

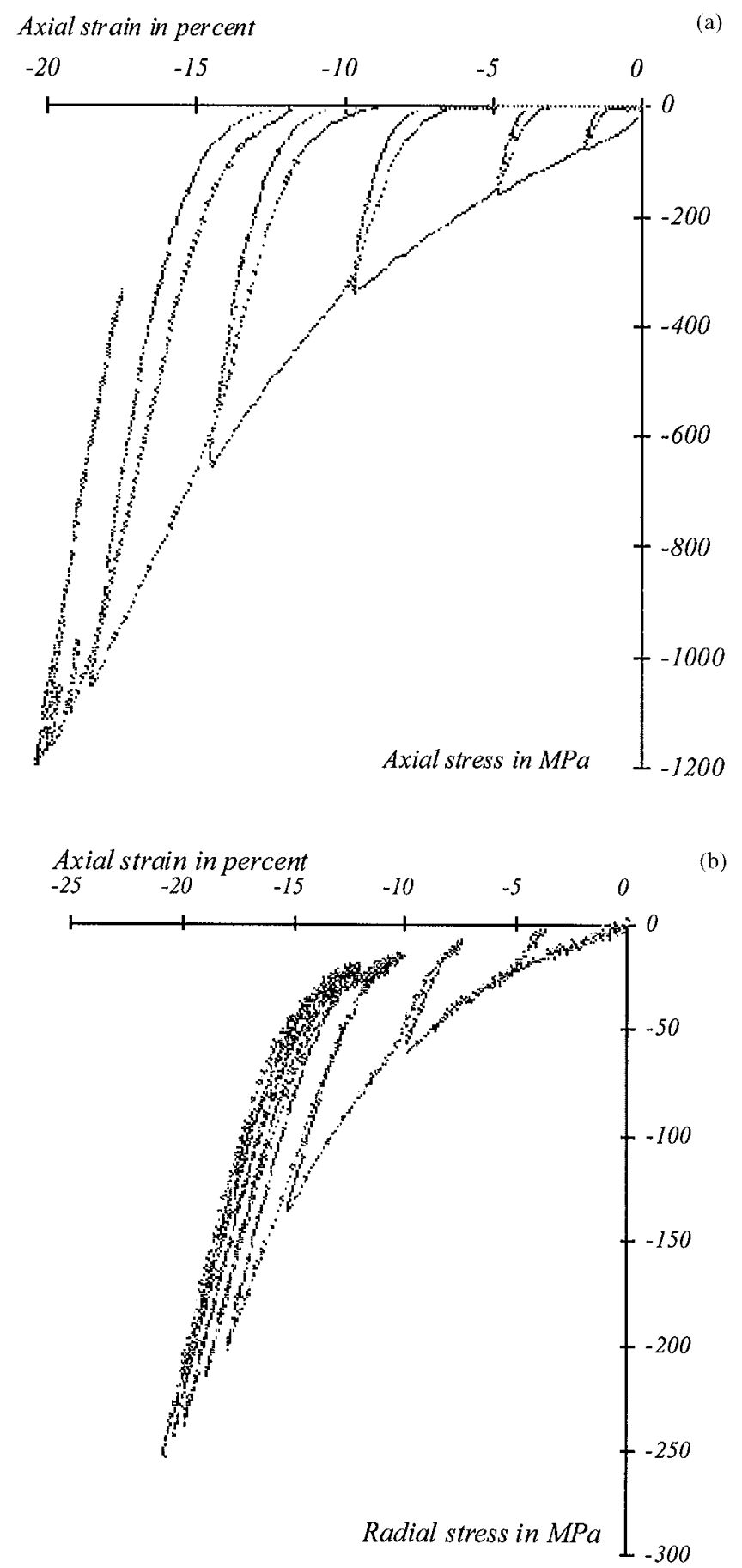

Figure 8. (a) Mortar results: axial strain versus axial stress curve. (b) Mortar results: axial strain versus radial stress curve. 


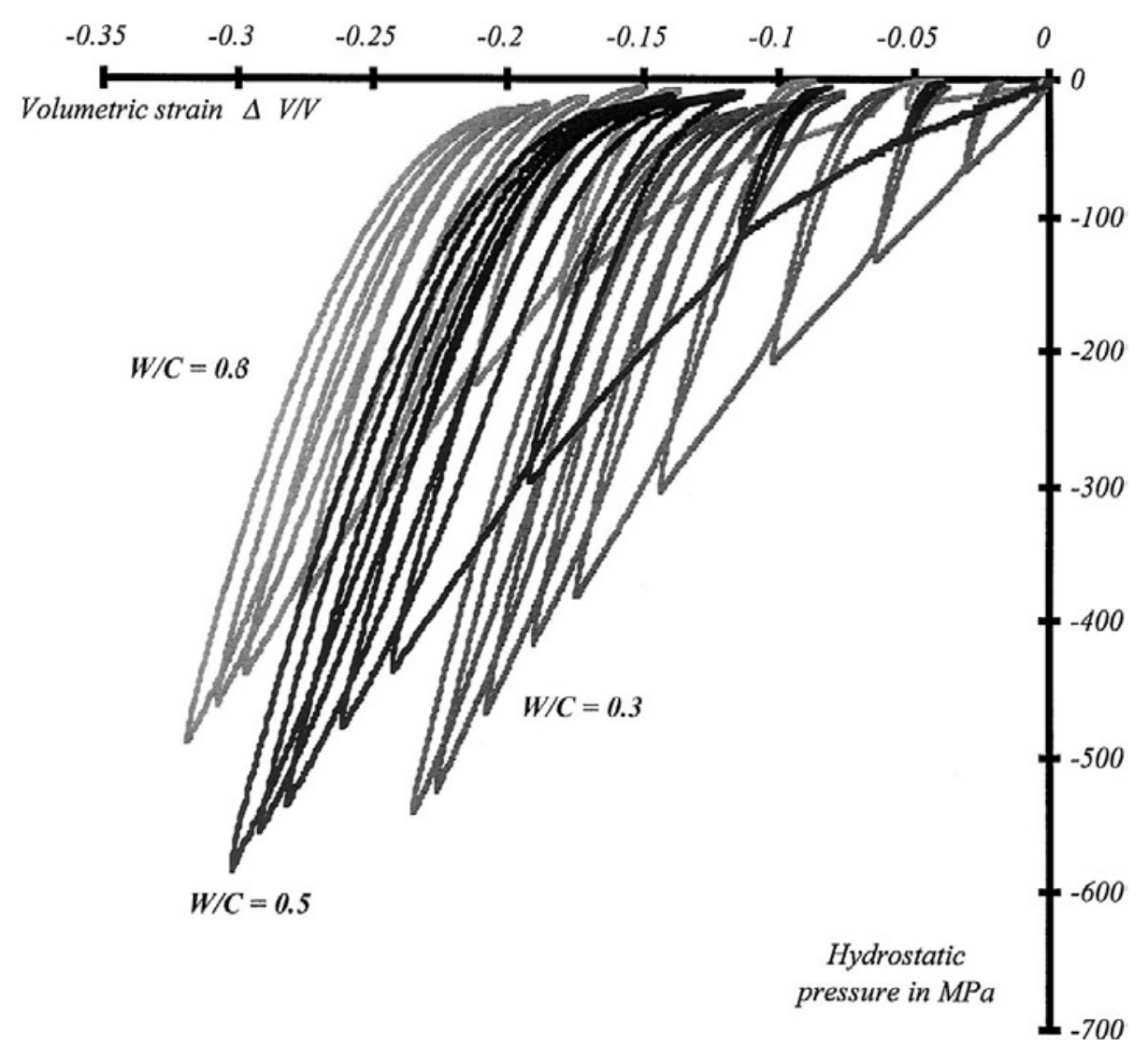

Figure 9. Volumetric strain versus hydrostatic pressure curve obtained on different mortars $(W / C=0.3,0.5,0.8)$.

Since concrete is porous material which is partly saturated with water, it is not clear whether the porous of structure of the material can be entirely crushed, which should inevitably produce water motion if the specimen is drained (which is not the case here). We do not intend to deal specifically with this problem in the present paper, but rather we present in Figure 13 a comparison with a dry concrete specimen. In these tests, the second concrete mix shown on Table II was used in order to augment the porosity of the material and the inherent water content. The dry specimen was cured for 2 weeks in an oven at constant temperature of $60^{\circ} \mathrm{C}$ with 0 per cent hygrometry. To verify that concrete was dry, the weight loss was measured every day. The end of drying corresponded to a loss of weight negligible over a few days. As expected, the dry specimen is more prone to compaction. The irreversible volumetric strain are larger for the dry specimen than for the normal one, for the same applied stress. At this stage, it is important to note that for water saturated concrete, the influence of porosity should depend on the permeability of the material in drained conditions, and on the compressibility of water for undrained conditions. 


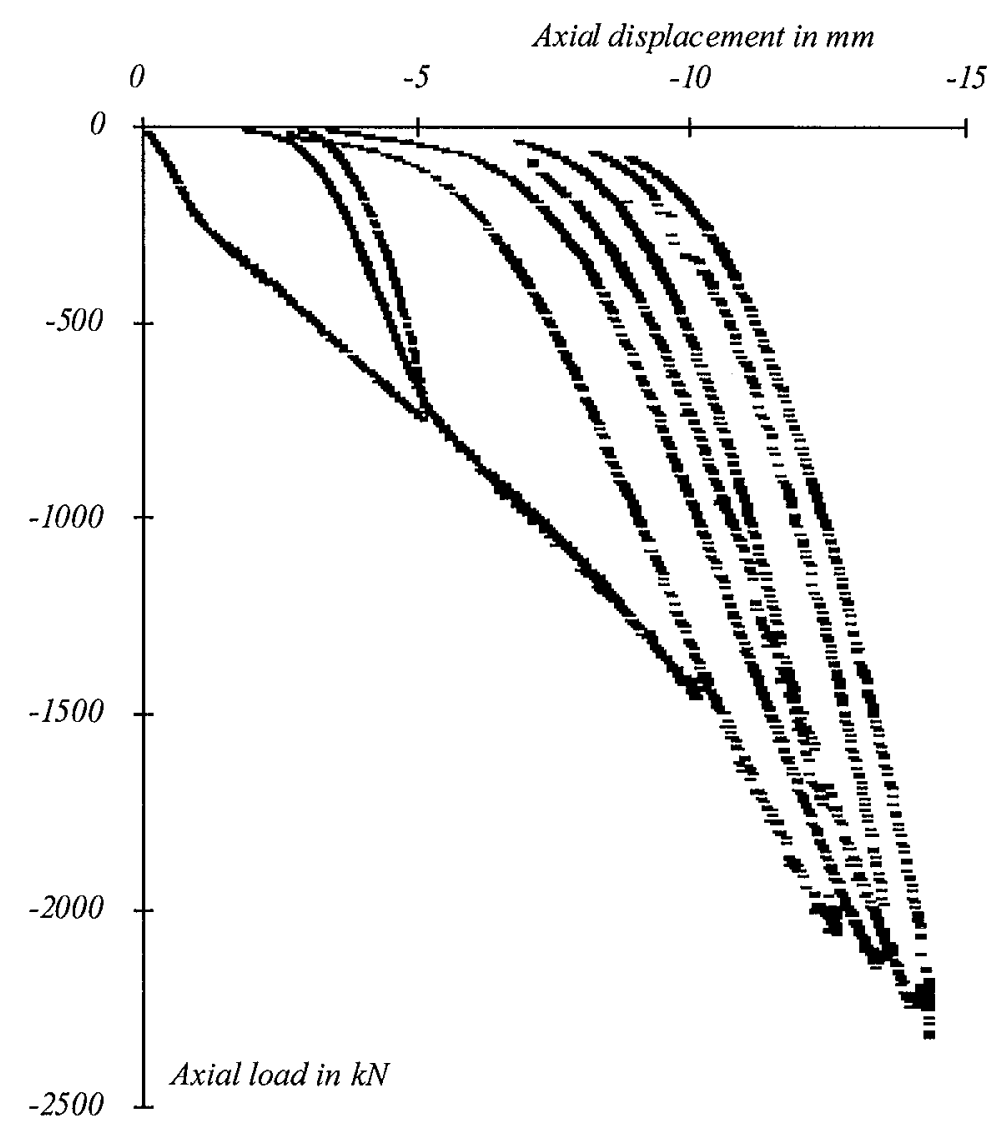

Figure 10. Axial displacement of jack versus axial load curve obtained on concrete $(W / C=0.5)$.

Table II. Mixes of tested concretes.

\begin{tabular}{ll}
\hline MIX 1 & Amount \\
\hline Gravel 5/16 mm & $1180 \mathrm{~kg} / \mathrm{m}^{3}$ \\
Sand 0/5 mm & $660 \mathrm{~kg} / \mathrm{m}^{3}$ \\
Cement CPJ/CEM IIb 45 & $350 \mathrm{~kg} / \mathrm{m}^{3}$ \\
Water & $175 \mathrm{~kg} / \mathrm{m}^{3}$ \\
\hline MIX 2 & Amount \\
\hline Gravel $5 / 16 \mathrm{~mm}$ & $1108 \mathrm{~kg} / \mathrm{m}^{3}$ \\
Sand 0/5 mm & $554 \mathrm{~kg} / \mathrm{m}^{3}$ \\
Cement CPJ/CEM IIb 45 & $380 \mathrm{~kg} / \mathrm{m}^{3}$ \\
Water & $247 \mathrm{~kg} / \mathrm{m}^{3}$ \\
\hline
\end{tabular}




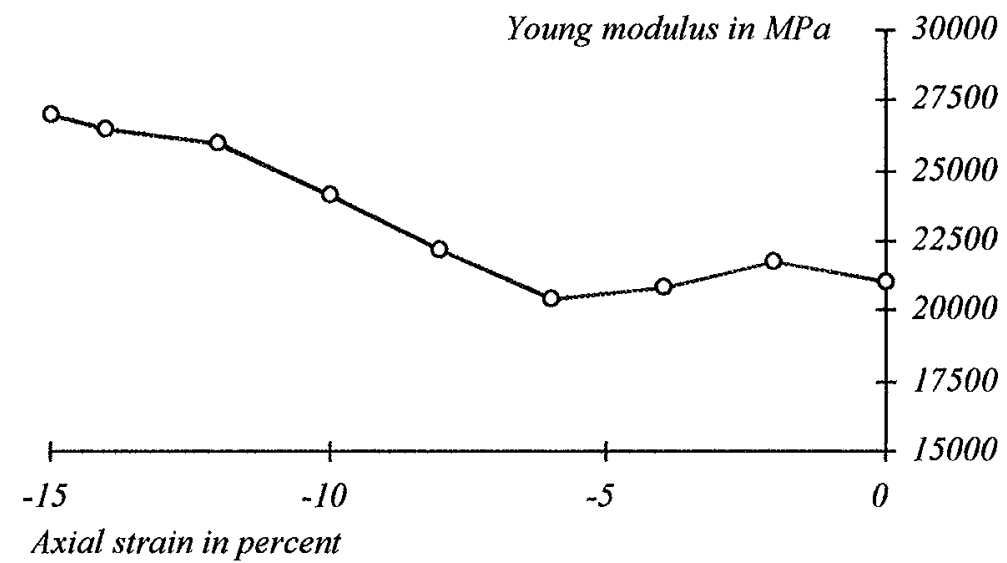

Figure 11. Evolution of Young's modulus during compaction for a concrete $(W / C=0.5)$.

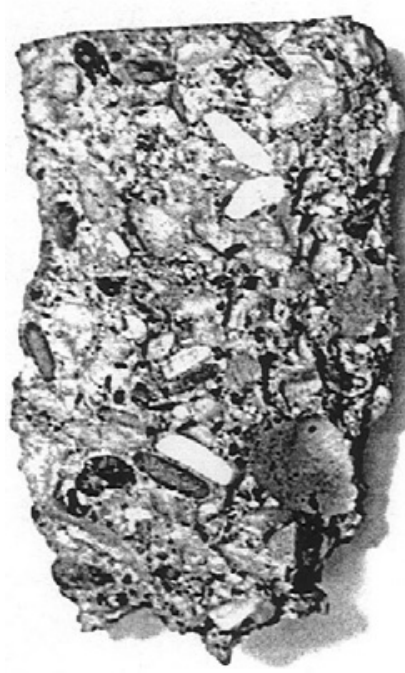

Initial state

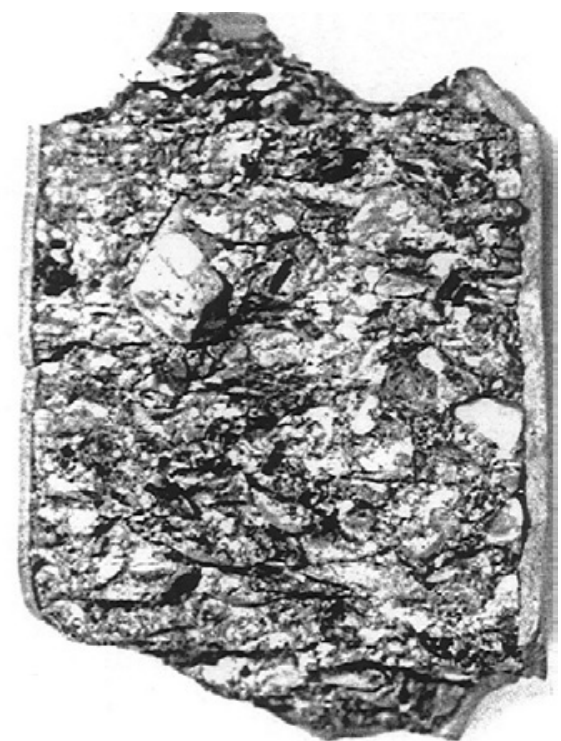

After compaction

Figure 12. Specimen before and after compaction.

\section{HYDROSTATIC TESTS AND COMPARISONS}

One problem of the uniaxial confined compression test is that it is not possible to control the state of stress applied on the concrete specimen unless the confinement cell is changed. In other words, this testing procedure provides an access to a single loading path, which is certainly the price to 


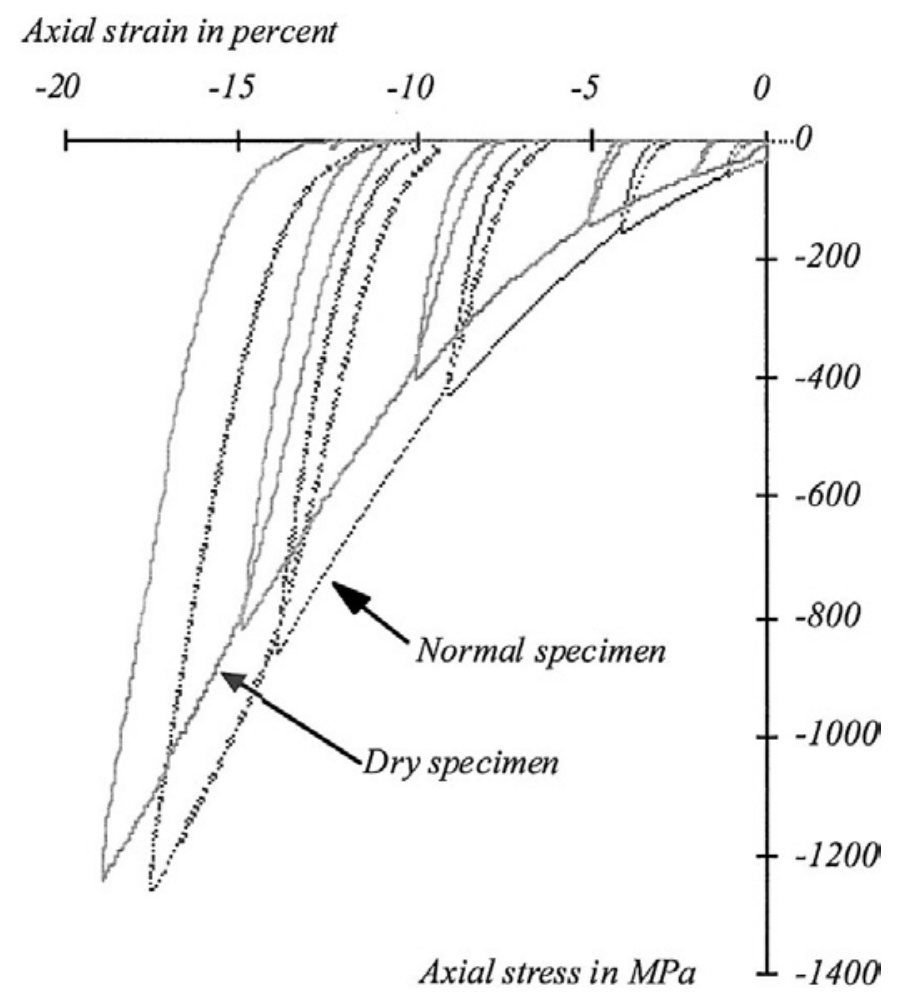

Figure 13. Axial strain versus axial stress curve for dry and normal mortars $(W / C=0.5)$.

pay for its practical simplicity. In order to exhibit the influence of the loading path on the hydrostatic response of the material, a second series of tests has been performed with a different testing device. This device has been developed by Dahan and tested by Gaillard [15] and Richard [16] for studying the response of metal alloys subjected to very high confinement pressure. It can be regarded as a standard triaxial cell which can apply a fluid hydrostatic pressure up to $400 \mathrm{MPa}$. The cell is shown in Figure 14. It cannot accommodate large specimens and mortar cylinders of diameter $18 \mathrm{~mm}$ and height $17 \mathrm{~mm}$ have been tested. The specimens are equipped with a rubber membrane in order to avoid any intrusion of the fluid into the pores of mortar and two strain gauges: one for the longitudinal strain and one for the transverse strain. They are covered with aluminium discs on the top and bottom faces which are necessary in the set-up because they serve as guides for the electrical cables connected to the strain gauges (Figure 15).

Results are presented here for the mortar specimens made with the mix $W / C=0.5$ as shown in Table I. Figure 16 shows a comparison of the transverse and longitudinal strains with increasing hydrostatic stress (fluid pressure). The data provided by the two gauges show that the state of deformation of the specimen is quite isotropic and that the aluminium discs do not interfere with the deformation of mortar. At the end of the hydrostatic test, the mortar specimen did not exhibit cracking, but its volume was reduced.

More interestingly, Figure 17 shows a comparison of the volumetric strain versus hydrostatic pressure curves obtained on the same mortar from the present testing device and the uniaxial 

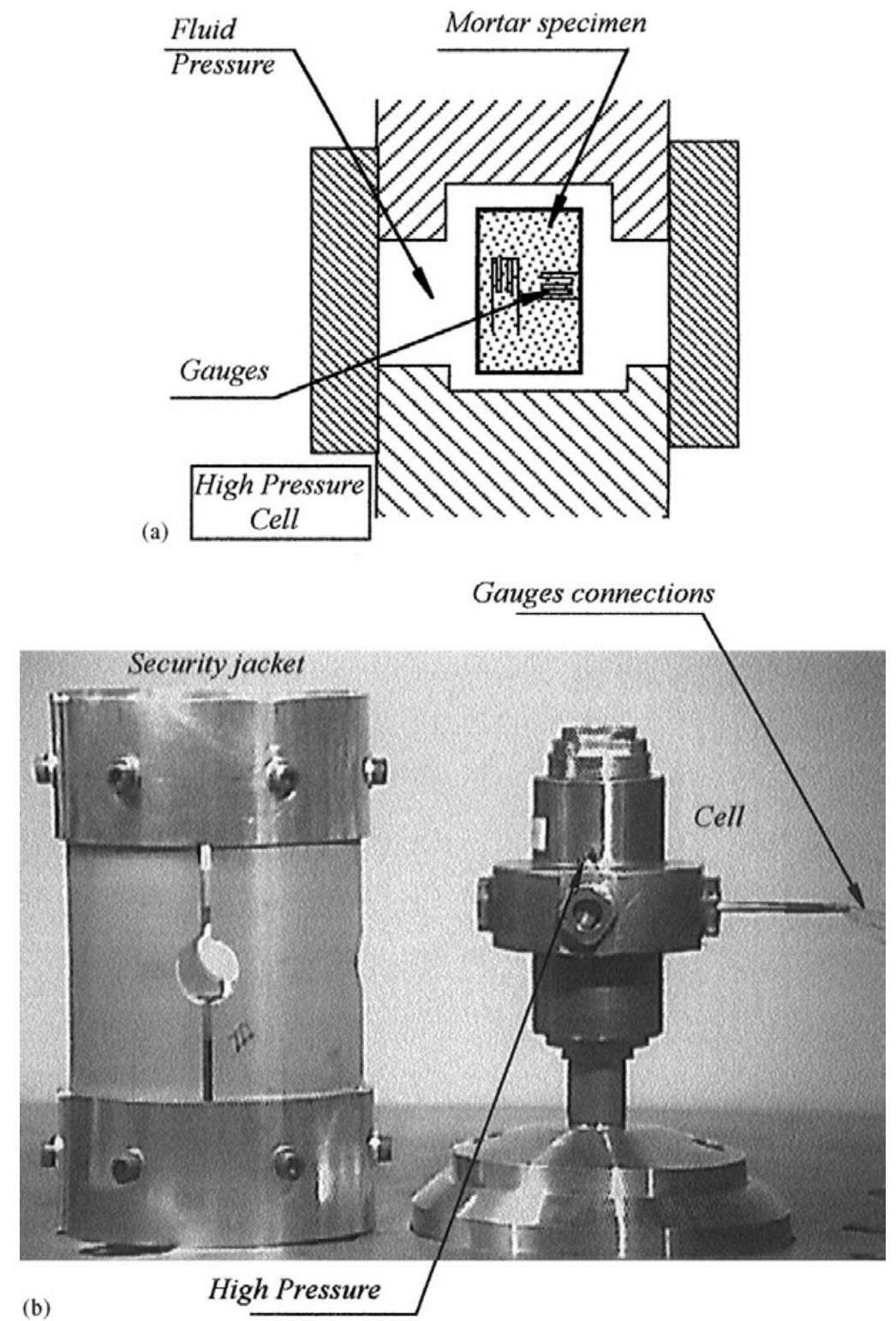

Figure 14. (a) Hydrostatic test principles. (b) Hydrostatic cell.

confined compression test. It is clear from this figure that a deviatoric stress very much influences the volumetric strain versus hydrostatic stress behaviour of the material. Hence, it is not possible in constitutive models to uncouple the hydrostatic and the deviatoric responses of this material. From a microstructural point of view, this sensitivity to the deviatoric stress could be expected because the porosity of the material is crushed in different ways depending on the deviatoric stress 

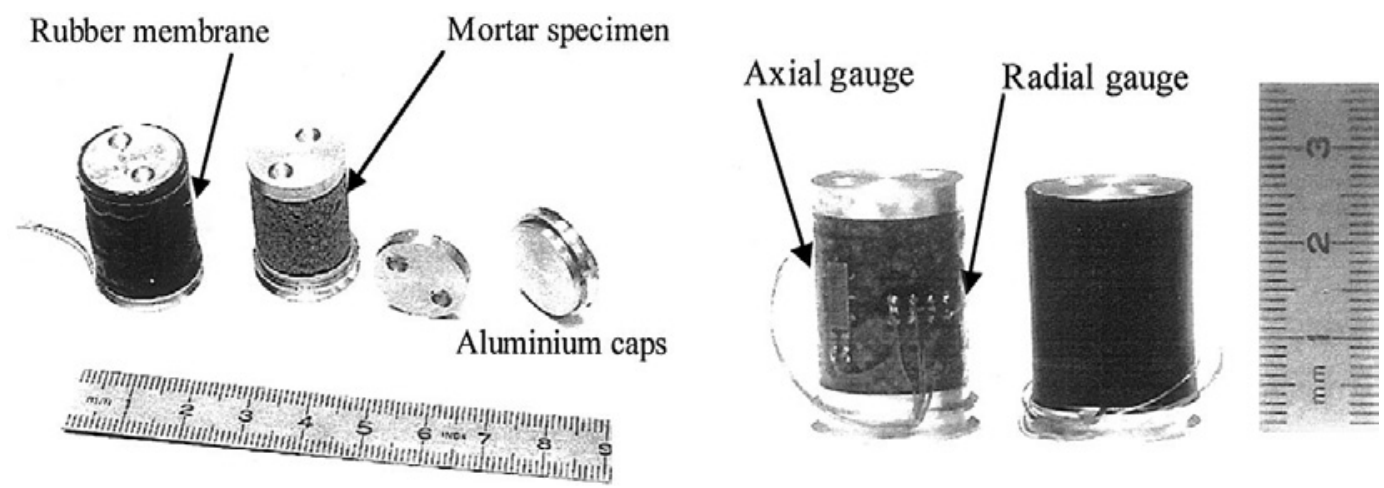

Figure 15. Mortar samples for the hydrostatic test.

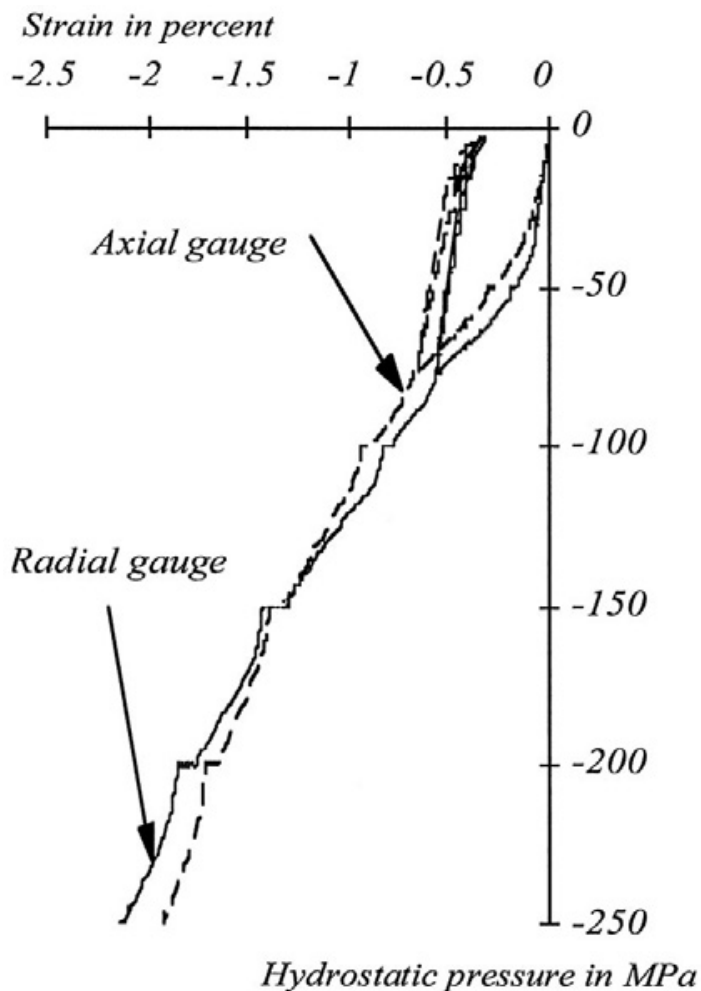

Figure 16. Strains versus hydrostatic pressure curves obtained for the radial and the longitudinal gauges.

applied on the material. Following this line of thinking, the same effect could be also expected on other porous materials. Bonnan [17] performed oedometric and hydrostatic tests on porous aluminium with different porosity. He found that the volumetric strain versus hydrostatic pressure curves deduced from the two testing procedures where exactly the same, although the 


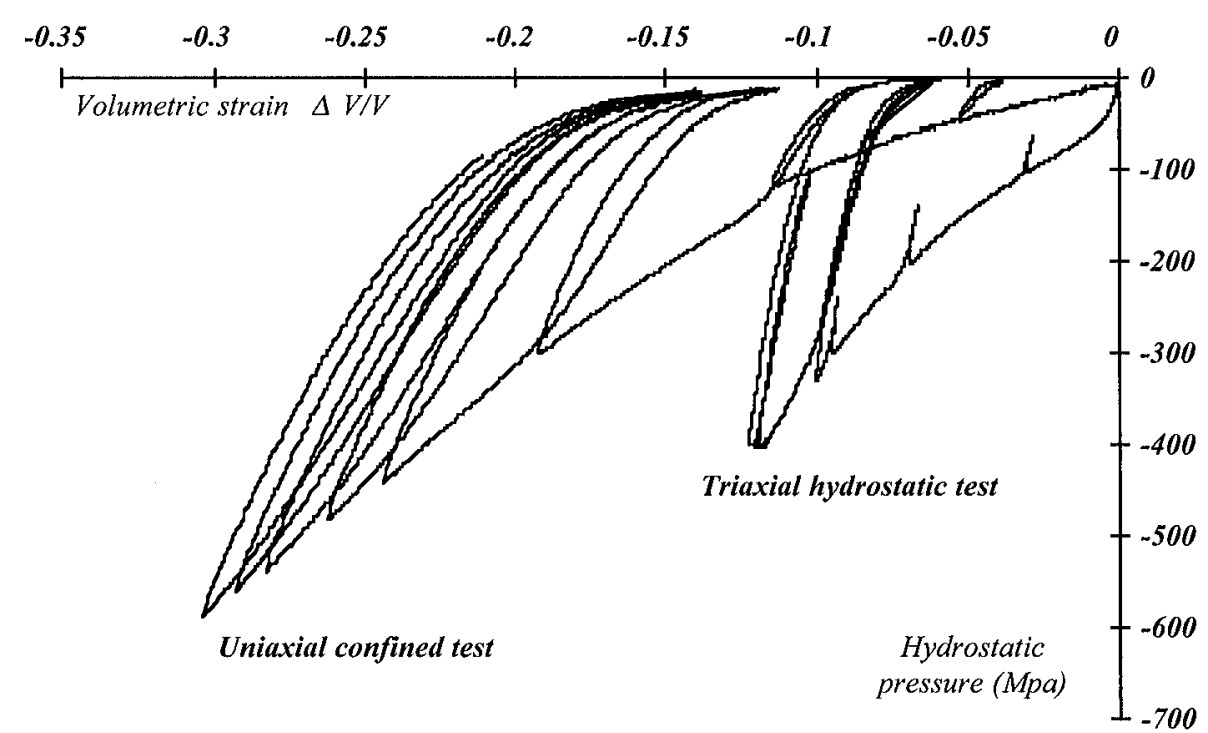

Figure 17. Experimental hydrostatic and oedometric tests results on mortar $(W / C=0.5)$.

magnitude of irreversible volumetric strains depends on the initial material porosity. Hence it seems that the coupling between the hydrostatic and deviatoric responses of the material is a feature due to the behaviour of the cementitious porous matrix and to the aggregate skeleton evolution in the course of loading. It is important to note that the domains of initial reversible behaviour are the same for the two curves on Figure 17. In fact, it is quite small, limited to hydrostatic pressures that are less than $50 \mathrm{MPa}$, as observed on Figures 16 and 9.

\section{CONCLUSIONS}

The hydrostatic response of concrete and mortar has been obtained experimentally with two testing methods. The uniaxial confined compression test is rather simple to implement as it is based on passive confinement. It is an extension of the technique used by Bazant et al. [13] which is inspired from testing procedures in geophysics and soil mechanics. An apparatus which can provide data on concrete and mortar has been described. Hydrostatic compression up to $600 \mathrm{MPa}$ can be applied. The interpretation of the measurement relies basically on standard elasticity formulas.

Results obtained from the uniaxial confined compression test show that the volumetric versus hydrostatic response of concrete and mortars exhibit a small reversible regime (for hydrostatic compression less than $400 \mathrm{MPa}$ for mortar) followed by an elasto-plastic regime where both the tangent moduli and bulk secant moduli increase as the result of compaction. The magnitude of the irreversible volumetric strains depends on the initial porosity of the material as shown by the experiments on mortar with different water to cement ratios. Volumetric strains should also 
depend on the degree of saturation of the material in undrained conditions. This topic should be dealt with in future research.

True hydrostatic tests have been also performed on small size mortar specimens. The comparison between the results obtained from the two testing methods shows that the hydrostatic response of the mortar depends a lot on the applied deviatoric stresses as opposed to results obtained on metal alloys. This features should be incorporated into constitutive relations aimed at describing the response of concrete under high compressive stresses such as in impact problems (see e.g. References $[18,19]$ ), along with a possible strain rate effect which has been characterized experimentally [20].

\section{ACKNOWLEDGEMENTS}

This study has been performed when the first two authors were affiliated with LMT-Cachan. Partial financial support from TDA Armements SAS is gratefully acknowledged.

\section{REFERENCES}

1. Ls-Dyna 3D. In Theoretical Manual, Hallquist JO (ed.). Livermore Software Technology Corporation: Livermore, USA, 1995.

2. Whirley RG, Hallquist JO, DYNA3D: a nonlinear explicit three-dimensional finite element code for solid and structural mechanics, user manual. Report UCRL-MA-10254, Lawrence Livermore National Laboratory, Livermore, USA, 1991.

3. Li H, Pugh D. Mechanical Behaviour of Materials Under Pressure. Elsevier: Amsterdam, 1970.

4. Van Mier JGM. Strain softening of concrete under multiaxial loading conditions. Doctoral Dissertation, Eindhoven University of Technology, The Netherlands, 1984.

5. Jamet P, Millard A, Nahas G. Triaxial behaviour of a micro-concrete complete stress-strain for confining pressures ranging from 0 to $100 \mathrm{MPa}$. Proceedings of the International Conference on Concrete under Multiaxial Conditions, vol. 1. Presses de l'Université Paul Sabatier: Toulouse, 1984; 133-140.

6. Mazars J, Pijaudier-Cabor G. Continuum damage theory: application to concrete. Journal of Engineering Mechanics, ASCE 1989; 115:345-365.

7. Winkler H. Fundamental investigations on the influence of test equipment on multiaxial test results of concrete. Proceedings of the International Conference on Concrete under Multiaxial Conditions, vol. 1. Presses de l'Université Paul Sabatier: Toulouse, France, 1984; 9-19.

8. Schickert G, Danssamann J. Behaviour of concrete stressed by high hydrostatic compression. Proceedings of the International Conference on Concrete under Multiaxial Conditions, vol. 2. Presses de l'Université Paul Sabatier: Toulouse, 1984; 69-84.

9. Le Vu O, Bailly P, Tombini C, Lalle P, Courchinoux C. Modélisation de géomatériaux sous sollicitations dynamiques élevées. II: Equation d'état du béton. Colloque du réseau GEO, Aussois 2-6 décembre, France, 1996.

10. Bridgman PW. The Physics of High Pressure, International Text-Books of Exact Science. G. Bell and Sons: London, 1958.

11. Boyds FR. In Modern Very High Pressure Technics, Wentorf RH (ed.). Butterworths: London, 1962.

12. Leger JM. Transformations de phases dans les solides ferromagnétiques sous très hautes pressions. Thèse, l'Université Pierre et Marie Curie (Paris VI), 1970.

13. Bazant ZP, Bishop FC, Chang TP. Confined compression tests of cement paste and concrete up to $300 \mathrm{Ksi}$. ACI Journal 1986; 33:553-560.

14. Gatuingt F, Pijaudier-Cabot G. Coupled damage and plasticity modelling in transient analysis of concrete. International Journal of Cohesive Frictional Materials 2001, in press.

15. Gaillard D. Contribution à la mise au point d'une enceinte haute pression pour l'étude de l'anisotropie induite. Master dissertation, Laboratoire de Mécanique et Technologie, CNAM, Paris, 1992.

16. Richard D. Contribution à la réalisation de générateurs pilotables pour l'analyse multidirectionnelle de surfaces seuils. Master dissertation, Laboratoire de Mécanique et Technologie, CNAM, Paris, 1993.

17. Bonnan $\mathrm{S}$. Modélisation mésomécanique du comportement sous choc de l'aluminium poreux — validation experimentale. Thèse de Doctorat, Université de Poitiers, France, 1996. 
18. Burlion, N. Compaction des bétons: Eléments de modélisation et charactérisation expérimentale. Doctoral dissertation, ENS de Cachan, Cachan, France, 1997.

19. Burlion, N, Gatuingt F, Pijaudier-Cabot G, Daudeville L. Compaction and Tensile Damage in Concrete: Constitutive Modelling and Application to Dynamics. Computer Methods in Applied Mechanics and Engineering 2000; 183:291-308.

20. Gatuingt F. Prévision de la rupture des ouvrages en béton sollicités en dynamique rapide. Doctoral Dissertation, ENS de Cachan, Cachan, France, 1999. 